\title{
RESEARCH
}

Open Access

\section{The impact of thrombocytopenia on prognosis of HBV-related small hepatocellular carcinoma: a propensity score matching analysis}

\author{
Wei Peng, Chuan Li, Xiaoyun Zhang, Tianfu Wen and Zheyu Chen *i]
}

\begin{abstract}
Background: Thrombocytopenia was reported both detrimental and advantageous to hepatocellular carcinoma (HCC). However, there is little evidence showing clearly the clinical value of preoperative thrombocytopenia on the surgical outcome of patients with small HCC. This retrospective study aimed at elucidating the correlation between preoperative thrombocytopenia and surgical outcome of small HCC patients within Milan criteria treated with liver resection.
\end{abstract}

Methods: Data of hepatitis B virus (HBV)-related small HCC patients were retrospectively analyzed, and we performed the propensity score matching (PSM) analysis to overcome the imbalance of clinicopathological features. Patients enrolled were subsequently categorized into two groups according to preoperative platelet counts: thrombocytopenia group and non-thrombocytopenia group. Survival outcomes of the patients in both groups were described with the Kaplan-Meier method, and the difference was compared with a log-rank test. Cox regression analysis was applied to identify the risk factors of surgical outcome.

Results: After PSM, the estimated 1-, 3-, and 5-year overall survival (OS) rates for small HCC patients in the thrombocytopenia group were $94.5 \%, 77.0 \%$, and $57.6 \%$, and $95.0 \%, 79.6 \%$, and 68.0\%, respectively, for small HCC patients in the non-thrombocytopenia group $(P=0.042)$. And the 1-, 3-, and 5-year estimated recurrence-free survival (RFS) rates for small HCC patients in the thrombocytopenia group were $70.4 \%, 51.0 \%$, and $42.1 \%$, and 83.8\%, 63.7\%, and 46.7\%, respectively, for small HCC patients in the non-thrombocytopenia group $(P=0.035)$. Multivariate analysis indicated preoperative thrombocytopenia was a significant prognosticator of poor RFS (hazard ratio $(H R)=1.388,95 \%$ confidence interval $(C l) 1.028 \sim 1.874, P=0.033)$.

Conclusion: Preoperative thrombocytopenia had an undesirable impact on the recurrence of small HCC patients treated with liver resection.

Keywords: Hepatocellular carcinoma, Liver resection, Platelet, Thrombocytopenia

\footnotetext{
* Correspondence: chenzheyu@scu.edu.cn Department of Liver Surgery \& Liver Transplantation Center, West China Hospital, Sichuan University, Chengdu 610041, China
}

(c) The Author(s). 2021 Open Access This article is licensed under a Creative Commons Attribution 4.0 International License, which permits use, sharing, adaptation, distribution and reproduction in any medium or format, as long as you give appropriate credit to the original author(s) and the source, provide a link to the Creative Commons licence, and indicate if changes were made. The images or other third party material in this article are included in the article's Creative Commons licence, unless indicated otherwise in a credit line to the material. If material is not included in the article's Creative Commons licence and your intended use is not permitted by statutory regulation or exceeds the permitted use, you will need to obtain permission directly from the copyright holder. To view a copy of this licence, visit http://creativecommons.org/licenses/by/4.0/ The Creative Commons Public Domain Dedication waiver (http://creativecommons.org/publicdomain/zero/1.0/) applies to the data made available in this article, unless otherwise stated in a credit line to the data. 


\section{Background}

Hepatocellular carcinoma (HCC) is reported to be a common malignancy with high rates of incidence and mortality [1]. Nearly $50 \%$ of the newly diagnosed cases and HCC-related deaths existed in China due to the large population and heavy burden of hepatitis $\mathrm{B}$ virus (HBV) infection [2]. Patients with small HCC meeting the Milan criteria which is a special subgroup of HCC are supposed to have a better prognosis than those beyond the Milan criteria [3]. Liver resection is reported to be the optimal choice for small HCC [4]. However, survival remains unsatisfactory after liver resection due to the high recurrence rate [5]. Continuous effort to predict recurrence following liver resection is needed.

Plenty of evidence showed platelets had multiple functions other than hemostasis and that they were also involved in inflammation, immunity, regeneration, and carcinogenesis of the liver [6]. The platelets' adhesion to tumor cells may form a "shield" which protects tumor cells from immune clearance [7]. Clinical data revealed that thrombocytosis was related to a worse prognosis in several malignancies [8, 9]. Prophylactic antiplatelet therapy was reported to reduce hepatocarcinogenesis in cirrhotic patients and decrease recurrence in $\mathrm{HCC}$ patients [10-12].

Thrombocytopenia, a symbol of liver cirrhosis and portal hypertension, has been reported to be associated with posthepatectomy liver failure (PHLF) and perioperative deaths [13]. Nevertheless, the clinical impact of thrombocytopenia on the long-term survival of HCC patients remains controversial. On one side, several studies have indicated that preoperative thrombocytopenia was a valuable predictor of recurrence and death for HCC patients [14-17]. On the other side, some recent studies found that thrombocytopenia was associated with better survival in patients with advanced HCC [18-21]. Furthermore, to our knowledge, there is no evidence showing the clinical value of thrombocytopenia on the long-term outcome of HBV-related small HCC patients within the Milan criteria.

The present retrospective study was performed to elucidate the clinical impact of thrombocytopenia on the surgical outcome of HBV-related small HCC patients.

\section{Methods}

This study was carried out with the approval of the Ethics Committee of our institute according to the Helsinki Declaration of 1975. Clinical data of HBV-related small HCC patients treated with liver resection between February 2007 and January 2016 in our center was collected from our prospective database. Histopathological characteristics including tumor differentiation, microvascular invasion (MVI), and liver cirrhosis were assessed by a hepatologist. In the current study, thrombocytopenia was defined as a platelet count less than $100 \times 10^{9} / \mathrm{L}$ according to a previous report [22].

The inclusion criteria of the present study were as follows: (1) pathologically confirmed HCC, (2) tumor within the Milan criteria, (3) treated with liver resection as the initial treatment, (4) normal liver function: ChildPugh class A, and (5) positive HBV surface antigen. The exclusion criteria are as follows: (1) extrahepatic malignancies and (2) poor data integrity.

\section{Follow-up}

The follow-up strategy was in accordance with the consensus we previously reported. Each patient was routinely followed up at the first month after surgery, trimonthly in the upcoming 3 years, and every 6 months subsequently [23]. Complete blood cell, liver function, concentration of alpha-fetoprotein (AFP), HBV-DNA level, and imaging examination should be included in each follow-up visit. Antiviral therapy would be initiated to patients according to the guideline suggestion. Recurrent $\mathrm{HCC}$ was diagnosed when typical features of $\mathrm{HCC}$ were revealed by two types of imaging examination or specific image finding along with an elevated AFP concentration. The final follow-up visit occurred on June 30, 2016.

\section{Statistical analysis}

Categorical data were displayed as numbers (percentage) and compared using the $\chi^{2}$ test, while the continuous variables were displayed as mean value \pm standard deviation and compared by the independent sample $t$ test. Survival outcomes in different groups were analyzed by the Kaplan-Meier method and were compared by a logrank test. Potential variables with a $P$ value of less than 0.05 in the univariate analysis were subsequently tested for proportional hazard assumption. Multivariate Cox regression analysis was used to investigate significant predictors for both overall survival (OS) and recurrencefree survival (RFS).

In this study, a PSM analysis was implemented to balance the bias of covariates. A multivariable logistic regression model was built to predict the probability of each patient being assigned to each group based on a set of known co-variables possibly affecting postoperative outcomes: age, gender, AFP level, liver function indicators, tumor size and number, liver cirrhosis, MVI, tumor differentiation, and transfusion. The predicted values were then used to obtain 1:1 nearest-neighbor matching with a caliper value of 0.2 . The nearest-neighbor matching was selected by matching the subject in the thrombocytopenia group to whose propensity score is closest to that of the subject in the non-thrombocytopenia group. Comparisons after propensity matching were calculated in terms of standardized mean difference. A 
difference less than $20 \%$ of absolute value was considered to be acceptable. Patients for whom the propensity score could not be matched exactly were excluded. Univariate and multivariate analyses were based on the data after PSM.

Statistics were accomplished by the SPSS software for Windows (version 25.0, IBM Corp, Armonk, NY, USA) and $\mathrm{R}$ software version 4.0.0 (R Foundation for Statistical Computing, Vienna, Austria; http://www.r-project.org). The R package of Survival was used for the proportional hazard assumption, and Jon Peck extension for PSM (version 1.5.0, IBM Corp, Armonk, NY, USA) was used for PSM analysis.

\section{Results}

\section{Patient features}

The present study enrolled as many as $582 \mathrm{HBV}$-related small HCC patients who underwent liver resection. PLT of the patients in the whole study ranged from $19 \times 10^{9}$ / $\mathrm{L}$ to $469 \times 10^{9} / \mathrm{L}$; among them, $247(42.4 \%)$ had a preoperative platelet count of $<100 \times 10^{9} / \mathrm{L}$ and were categorized as the thrombocytopenia group, while 335 (57.6\%) had a preoperative platelet count of $\geq 100 \times 10^{9} /$ $\mathrm{L}$ and were categorized as the non-thrombocytopenia group. Table 1 shows the detailed clinicopathologic features of patients in these two groups. The comparison of several indicators of the liver function between the two groups revealed that patients in the nonthrombocytopenia group exhibited a lower incidence of underlying liver cirrhosis, lower total bilirubin, higher serum albumin, and shorter prothrombin time $(P<$ $0.05)$. Nevertheless, patients from the thrombocytopenia group had smaller but multiple tumors $(P<0.05)$. After the PSM, 201 matched pairs were created for further analysis. The baseline features were comparable between those two matched cohorts (Table 1).

\section{Impact of thrombocytopenia on survival}

After 35 months of median follow-up time, 241 (41.4\%) patients were found recurrent and 148 (25.4\%) patients died. Before PSM, 1-, 3-, and 5-year estimated OS rates of patients in the thrombocytopenia group were $93.3 \%, 74.9 \%$, and $55.5 \%$, separately, and $95.1 \%$, $77.6 \%$, and $68.2 \%$, separately, for patients in the nonthrombocytopenia group, respectively $(P=0.029)$. One-, 3-, and 5-year estimated RFS rates of patients in the thrombocytopenia group were $71.1 \%, 50.9 \%$, and $41.4 \%$, separately, and $81.1 \%, 62.7 \%$, and $50.0 \%$, separately, for patients in the non-thrombocytopenia group, respectively $(P=0.010$, Fig. $1 \mathrm{a})$.

After PSM, 1-, 3-, and 5-year estimated OS rates of patients in the thrombocytopenia group were $94.5 \%, 77.0 \%$, and $57.6 \%$, separately, and $95.0 \%, 79.6 \%$, and $68.0 \%$, separately, for patients in the non-thrombocytopenia group, respectively $(P=0.042)$. One-, $3-$, and 5 -year estimated RFS rates of patients in the thrombocytopenia group were $70.4 \%, 51.0 \%$, and $42.1 \%$, separately, and $83.8 \%, 63.7 \%$, and $46.7 \%$, separately, for patients in the non-thrombocytopenia group, respectively $(P=0.035$, Fig. 1b).

Table 1 Baseline features of two groups based on preoperative platelet counts

\begin{tabular}{|c|c|c|c|c|c|c|}
\hline \multirow[t]{2}{*}{ Variables } & \multicolumn{3}{|c|}{ Whole study population } & \multicolumn{3}{|c|}{ Propensity score-matched pairs } \\
\hline & $\begin{array}{l}\mathrm{PLT}<100\left(\times 10^{9} / \mathrm{L}\right) \\
n=247\end{array}$ & $\begin{array}{l}\mathrm{PLT} \geq 100\left(\times 10^{9} / \mathrm{L}\right) \\
n=335\end{array}$ & $P$ & $\begin{array}{l}\mathrm{PLT}<100\left(\times 10^{9} / \mathrm{L}\right) \\
n=201\end{array}$ & $\begin{array}{l}\text { PLT } \geq 100\left(\times 10^{9} / L\right) \\
n=201\end{array}$ & $P$ \\
\hline Age (years) & $51.18 \pm 11.04$ & $49.36 \pm 11.37$ & 0.054 & $50.25 \pm 11.38$ & $50.06 \pm 12.07$ & 0.872 \\
\hline Male/female & $207 / 40$ & $288 / 47$ & 0.482 & $173 / 28$ & $164 / 37$ & 0.278 \\
\hline AFP $>400 \mathrm{ng} / \mathrm{mL}$ & $76(30.8 \%)$ & $100(29.9 \%)$ & 0.855 & $62(30.8 \%)$ & $63(31.3 \%)$ & 1.000 \\
\hline TBIL $(\mu \mathrm{mol} / \mathrm{L})$ & $16.65 \pm 6.70$ & $14.33 \pm 6.00$ & $<0.001$ & $15.61 \pm 5.51$ & $15.57 \pm 6.71$ & 0.941 \\
\hline ALB (g/L) & $41.53 \pm 4.40$ & $42.52 \pm 5.03$ & 0.014 & $42.15 \pm 3.99$ & $42.11 \pm 4.41$ & 0.921 \\
\hline $\mathrm{ALT}(\mathrm{IU} / \mathrm{L})$ & $47.82 \pm 35.86$ & $47.20 \pm 46.75$ & 0.862 & $48.44 \pm 37.47$ & $45.96 \pm 42.20$ & 0.533 \\
\hline AST (IU/L) & $42.45 \pm 25.12$ & $39.48 \pm 39.64$ & 0.302 & $41.19 \pm 25.29$ & $39.38 \pm 35.53$ & 0.556 \\
\hline PT (s) & $12.43 \pm 1.20$ & $12.02 \pm 1.09$ & $<0.001$ & $12.25 \pm 1.14$ & $12.17 \pm 1.13$ & 0.517 \\
\hline CREA $(\mu \mathrm{mol} / \mathrm{L})$ & $77.23 \pm 24.14$ & $75.94 \pm 14.13$ & 0.422 & $77.11 \pm 15.15$ & $75.60 \pm 15.28$ & 0.318 \\
\hline Tumor size $<3 \mathrm{~cm}$ & $140(56.9 \%)$ & $160(47.8 \%)$ & 0.036 & $106(52.7 \%)$ & $112(55.7 \%)$ & 0.617 \\
\hline Solitary tumor & $212(85.8 \%)$ & $308(91.9 \%)$ & 0.021 & $180(89.6 \%)$ & $184(91.5 \%)$ & 0.610 \\
\hline Transfusion (+/-) & $26 / 221$ & $10 / 325$ & $<0.001$ & 10/191 & 10/191 & 1.000 \\
\hline Cirrhosis (+/-) & $231 / 16$ & $270 / 65$ & $<0.001$ & $186 / 15$ & $187 / 14$ & 1.000 \\
\hline $\mathrm{MVI}(+/-)$ & $49 / 198$ & $47 / 288$ & 0.071 & $40 / 161$ & $37 / 164$ & 0.800 \\
\hline Poor differentiation & 99 (40.1\%) & $113(33.7 \%)$ & 0.117 & $84(41.8 \%)$ & 79 (39.3\%) & 0.685 \\
\hline
\end{tabular}

PLT platelet counts, AFP alpha-fetoprotein, TBIL total bilirubin, $A L B$ albumin, ALT alanine aminotransferase, $A S T$ aspartate aminotransferase, $P T$ prothrombin time, CREA creatinine, MVI microvascular invasion 

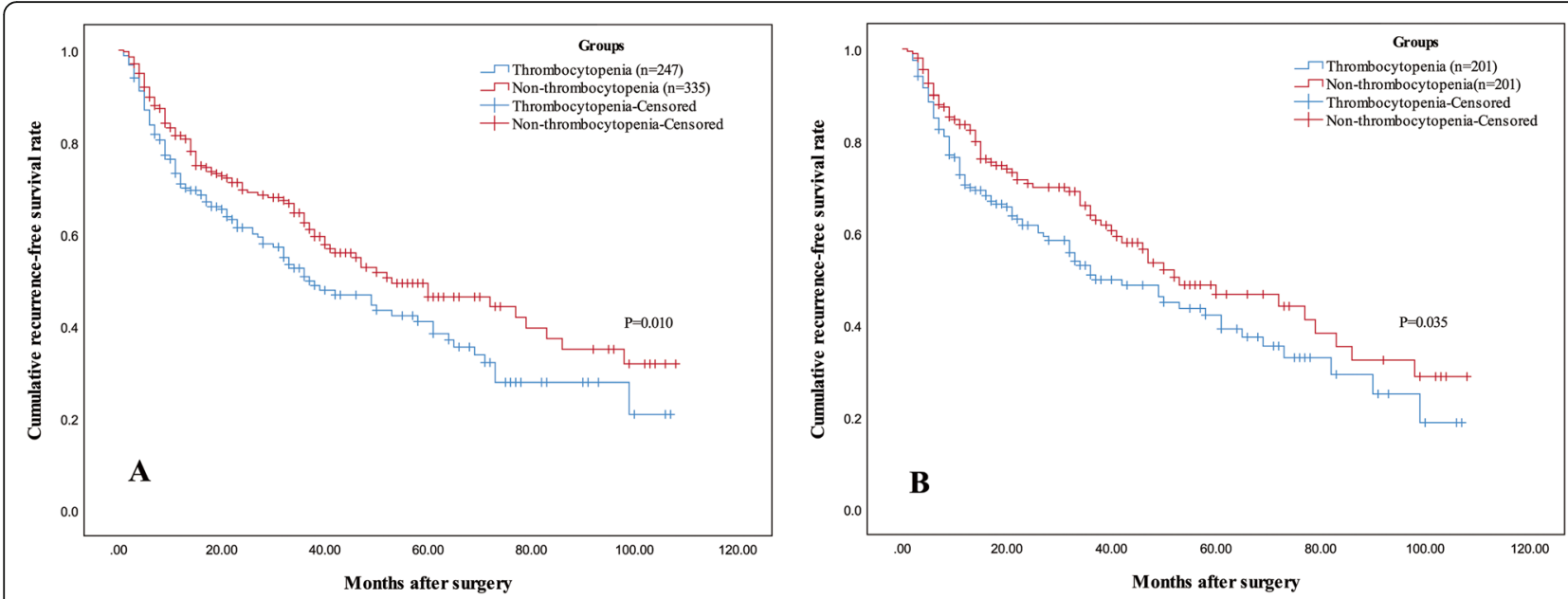

Fig. 1 Kaplan-Meier curves of RFS for small HCC patients in the thrombocytopenia and non-thrombocytopenia groups before (a) and after (b) PSM. Patients in the thrombocytopenia group had decreased recurrence-free survival before (a) and after (b) PSM. RFS, recurrence-free survival; HCC, hepatocellular carcinoma; PSM, propensity score matching

\section{Independent risk factors of prognosis}

After PSM, univariate analysis suggested that creatinine $(P=0.012)$, presence of MVI $(P<0.001)$, poor differentiation $(P<0.001)$, and thrombocytopenia $(P=0.042)$ were related to reduced OS. These four covariates all meet proportional hazard assumption (Supplementary Table 1). Cox regression analysis suggested that elevated creatinine $(\mathrm{HR}=1.014,95 \% \mathrm{CI} 1.002 \sim 1.027, P$ $=0.025)$ and presence of MVI $(\mathrm{HR}=2.628,95 \% \mathrm{CI}$
1.759 3.925, $P<0.001)$ were prognostic factors for reduced OS (Table 2). Univariate analysis found poor differentiation $(P<0.001)$, multiple tumors $(P=0.004)$, presence of MVI $(P<0.001)$, and thrombocytopenia $(P<$ 0.001 ) were significantly related to recurrence. These four covariates all meet proportional hazard assumption (Supplementary Table 1). Then, Cox regression suggested poor differentiation $(\mathrm{HR}=1.399,95 \% \mathrm{CI} 1.024 \sim 1.911, P=$ 0.035), multiple tumors $(\mathrm{HR}=2.561,95 \%$ CI 1.658 3.955,

Table 2 Prognostic factors of overall survival in propensity score-matched pairs

\begin{tabular}{|c|c|c|c|c|}
\hline \multirow[t]{2}{*}{ Factors } & \multicolumn{2}{|l|}{ Univariate analysis } & \multicolumn{2}{|c|}{ Multivariate analysis } \\
\hline & $\mathrm{HR}(95 \% \mathrm{Cl})$ & $P$ & $\mathrm{HR}(95 \% \mathrm{Cl})$ & $P$ \\
\hline Age & $0.996(0.977 \sim 1.015)$ & 0.657 & & \\
\hline Gender (male) & 1.709 (0.874 3.340) & 0.117 & & \\
\hline TBIL & $0.996(0.961 \sim 1.033)$ & 0.844 & & \\
\hline ALT & 1.004 (0.999 1.009) & 0.160 & & \\
\hline AST & $1.002(0.996 \sim 1.009)$ & 0.484 & & \\
\hline ALB & $0.969(0.920 \sim 1.021)$ & 0.241 & & \\
\hline PT & $0.969(0.795 \sim 1.181)$ & 0.757 & & \\
\hline CREA & 1.019 (1.004 1.034) & 0.012 & $1.014(1.002 \sim 1.027)$ & 0.025 \\
\hline $\operatorname{AFP}(>400 \mathrm{ng} / \mathrm{mL})$ & $1.421(0.890 \sim 2.269)$ & 0.141 & & \\
\hline Tumor size $(3 \sim 5 \mathrm{~cm})$ & $1.326(0.850 \sim 2.069)$ & 0.214 & & \\
\hline Tumor number (2 3) & 2.214 (1.114 4.399) & 0.023 & & \\
\hline Transfusion (+) & $1.539(0.597 \sim 3.968)$ & 0.372 & & \\
\hline Cirrhosis (+) & $1.136(0.471 \sim 2.741)$ & 0.777 & & \\
\hline $\mathrm{MVI}(+)$ & $3.432(2.040 \sim 5.773)$ & $<0.001$ & $2.628(1.759 \sim 3.925)$ & $<0.001$ \\
\hline Poor differentiation (+) & $3.579(2.251 \sim 5.691)$ & $<0.001$ & & \\
\hline $\operatorname{PLT}\left(<100 \times 10^{9} / \mathrm{L}\right)$ & $1.592(1.016 \sim 2.493)$ & 0.042 & & \\
\hline
\end{tabular}

HR hazard ratio, $C I$ confidence interval, $T B I L$ total bilirubin, $A L T$ alanine aminotransferase, $A S T$ aspartate aminotransferase, $A L B$ albumin, $P T$ prothrombin time, $C R E A$ creatinine, AFP alpha-fetoprotein, MVI microvascular invasion, $P L T$ platelet counts 
$P<0.001)$, presence of MVI $(\mathrm{HR}=1.970,95 \% \mathrm{CI}$ 1.407 2.757, $P<0.001$ ), and thrombocytopenia (HR = $1.388,95 \%$ CI $1.028 \sim 1.874, P=0.033$ ) were found to be prognostic factors for reduced RFS (Table 3 ).

\section{Discussion}

Much attention has been given to the prognostic value of platelets, which has the advantage of being readily available from routine test of blood cells. Thrombocytopenia per se was reported to cause different outcomes in HCC patients. The results of this retrospective study demonstrated preoperative thrombocytopenia a reliable prognosticator of decreased RFS for small HCC.

Bihari et al. reported the association of platelets with HCC after analyzing consecutive 1008 cirrhosis and 420 HCC cases [18]. In their study, platelet counts increased after carcinogenesis from cirrhosis and decreased after treatment, and this phenomenon indicated that platelets may be stimulated by the HCC-related factors. Both systemic inflammatory response and HCC followed by chronic liver disease are often associated with elevated interleukin-6 (IL-6) levels which stimulates thrombopoiesis through thrombopoietin [24]. In other words, HCC would thus induce the increase of platelet counts. Platelets play a significant part in inflammation, fibrogenesis, and oncogenesis of the liver [6]. In a study on mice infected by HBV, researchers pointed out that platelets took a part in the etiopathogenesis of HCC [25]. Platelets facilitate invasion and metastasis of cancers by the formation of platelet coating shielding cancer cells and evading immune detection [26]. Increase of angiogenesis factors initiated by platelet activation would also promote tumor growth [27].

Thrombocytopenia is reported to be the most common hematologic complication in cirrhotic patients [28]. Decreased thrombopoietin production in the liver and increased platelet sequestration in the spleen followed by liver cirrhosis and hypersplenism were the major mechanisms of thrombocytopenia [22, 29]. A previous research also reported that degrees of impaired hepatic function may vary even in the same Child-Pugh class [30]. In line with that, we observed that patients in the thrombocytopenia group exhibited worse liver function reserve and higher incidence of cirrhosis (Table 1). Previous studies have confirmed that both liver cirrhosis and liver function reserve were strong predictors for postoperative recurrence of HCC $[31,32]$. It was confirmed in the present study that patients in the thrombocytopenia group had an increased risk of postoperative recurrence. Interestingly, we also found patients in the thrombocytopenia group trended to have smaller but more tumors $(P<0.05)$, and tumor number $(2 \sim 3)$ but not tumor size was found to be an independent risk factor of recurrence in Cox regression. Kubo and his colleagues also found a strong correlation between thrombocytopenia and multicentricity of HCC [33]. Thrombocytopenia caused by extensive fibrosis/cirrhosis which was related to worse liver function reserve

Table 3 Prognostic factors of recurrence-free survival in propensity score-matched pairs

\begin{tabular}{|c|c|c|c|c|}
\hline \multirow[t]{2}{*}{ Factors } & \multicolumn{2}{|l|}{ Univariate analysis } & \multicolumn{2}{|c|}{ Multivariate analysis } \\
\hline & HR (95\% Cl) & $P$ & HR $(95 \% \mathrm{Cl})$ & $P$ \\
\hline Age & $0.993(0.976 \sim 1.010)$ & 0.421 & & \\
\hline Gender (male) & 1.587 (0.909 2.769) & 0.104 & & \\
\hline TBIL & 0.995 (0.963 1.028) & 0.758 & & \\
\hline ALT & $1.003(0.998 \sim 1.008)$ & 0.199 & & \\
\hline AST & 1.006 (0.999 1.013) & 0.111 & & \\
\hline ALB & $0.963(0.918 \sim 1.009)$ & 0.116 & & \\
\hline PT & $0.894(0.748 \sim 1.068)$ & 0.215 & & \\
\hline CREA & $1.007(0.994 \sim 1.020)$ & 0.300 & & \\
\hline $\operatorname{AFP}(>400 \mathrm{ng} / \mathrm{mL})$ & $1.163(0.760 \sim 1.780)$ & 0.485 & & \\
\hline Tumor size $(3 \sim 5 \mathrm{~cm})$ & $1.077(0.725 \sim 1.601)$ & 0.714 & & \\
\hline Tumor number (2 3) & 2.807 (1.391 5.664) & 0.004 & $2.561(1.658 \sim 3.955)$ & $<0.001$ \\
\hline Transfusion (+) & 0.877 (0.350 2.194) & 0.779 & & \\
\hline Cirrhosis (+) & $1.744(0.774 \sim 3.931)$ & 0.180 & & \\
\hline $\mathrm{MVI}(+)$ & 2.837 (1.694 4.750) & $<0.001$ & $1.970(1.407 \sim 2.757)$ & $<0.001$ \\
\hline Poor differentiation (+) & 3.778 (2.483 5.750) & $<0.001$ & $1.399(1.024 \sim 1.911)$ & 0.035 \\
\hline $\operatorname{PLT}\left(<100 \times 10^{9} / \mathrm{L}\right)$ & $1.534(1.031 \sim 2.282)$ & 0.035 & $1.388(1.028 \sim 1.874)$ & 0.033 \\
\hline
\end{tabular}

$H R$ hazard ratio, $C I$ confidence interval, TBIL total bilirubin, $A L T$ alanine aminotransferase, AST aspartate aminotransferase, $A L B$ albumin, $P T$ prothrombin time, CREA creatinine, AFP alpha-fetoprotein, MVI microvascular invasion, PLT platelet counts 
and multicentricity of $\mathrm{HCC}$ might promote tumor recurrence after liver resection.

Nouso et al. revealed thrombocytopenia a significant risk factor of intrahepatic distant recurrence for HCC patients who underwent local ablation therapies [34]. He proposed that multicentric occurrence of $\mathrm{HCC}$ served as a feasible explanation for the close correlation between intrahepatic recurrence and underlying hepatic factors including thrombocytopenia. Similarly, thrombocytopenia was reported to be related to poor OS after radiofrequency ablation for HCC [16]. Moreover, Amano et al. found that thrombocytopenia predicted postoperative death and recurrence for HCC patients exceeding the Milan criteria [14]. Besides, results from two western centers revealed that a pretreatment platelet count less than $150 \times 10^{9} / \mathrm{L}$ was a significant prognosticator of poor surgical outcome for patients with $\mathrm{HCC} \leq 2 \mathrm{~cm}$ [15]. In the present study, we used a PSM analysis to balance the bias between the two groups and found preoperative thrombocytopenia an independent risk factor of RFS for HBV-related small HCC within the Milan criteria treated with liver resection. Patients included in the abovementioned studies shared a common character of early-stage HCC. Thrombocytopenia, the common complication of cirrhosis plays a negative impact on the prognosis of early-stage HCC.

However, some other studies found that HCC patients accompanied with thrombocytopenia had favorable outcomes. Morimoto and his colleagues found that HCC patients accompanied with thrombocytopenia were at lower risk of extrahepatic metastasis [19]. In their study, high platelet counts were significantly associated with the presence of portal vein tumor thrombus (PVTT) which was a strong predictor of extrahepatic metastasis. Xue et al. reported a similar result that high platelet counts increased the risk of extrahepatic metastasis of huge HCC treated with transcatheter arterial chemoembolization (TACE) [35]. Recently, Cheng et al. reported that preoperative thrombocytopenia was closely related to a favorable outcome of HCC patients with PVTT treated with liver resection [20]. Furthermore, several studies suggested that antiplatelet treatment helped to decrease the risk of hepatocarcinogenesis and recurrence of HCC $[10,11,36]$. Antiplatelet therapy served as an anti-HCC agent via decreasing epithelial angiogenesis and modulating systemic inflammation $[37,38]$.

We attempted to compromise the paradox of thrombocytopenia being both detrimental and advantageous to HCC. The pathophysiology of thrombocytopenia in HCC patients is complex since portal hypertension and hypersplenism followed by liver cirrhosis would lead to reduced platelet counts while systematic inflammation driven by HCC would increase platelet counts [39]. We hypothesized that biological behavior of tumor or liver function reserve would play a decisive role in the prognosis of $\mathrm{HCC}$ in different stages of HCC. Liver function reserve plays the decisive role in the prognosis of early-stage $\mathrm{HCC}$, while the biological behavior of early-stage HCC is less malignant. HCC patients with thrombocytopenia which indicates worse liver function reserve would thus have a worse prognosis. On the other side, biological behavior plays the decisive role in prognosis of advanced-stage HCC, HCC patients with thrombocytopenia which reflected less thrombopoietin and IL- 6 induced by less malignant tumor would have a better prognosis. This hypothesis helps to explain why studies based on different patient populations reached different conclusions. Studies [15-17, 34] that enrolled early-stage HCC patients who received liver resection or ablation suggested that thrombocytopenia was associated with poor prognosis, while studies $[19,20,35]$ that enrolled advanced-stage HCC patients who received TACE or liver section suggested thrombocytopenia was associated with favorable prognosis.

Several limitations exist in this study. First, HCC patients enrolled in the present study are HBV-related, while most $\mathrm{HCC}$ cases are related to hepatitis $\mathrm{C}$ virus and alcohol in Western countries. So, the results of the present study should be further validated by a different etiological population. Second, there might be potential selection bias even though we used PSM analysis to balance the bias due to the mono-center, retrospective nature of this study.

\section{Conclusions}

In conclusion, the present study found that preoperative thrombocytopenia had an undesirable impact on postoperative recurrence of $\mathrm{HBV}$-related small HCC patients.

\section{Supplementary Information}

The online version contains supplementary material available at https://doi. org/10.1186/s12957-021-02160-2.

Additional file 1: Table 1. Results of proportional hazard assumption before Cox regression for OS and RFS.

\section{Abbreviations}

HCC: Hepatocellular carcinoma; PSM: Propensity score matching; OS: Overall survival; RFS: Recurrence-free survival; HBV: Hepatitis B virus;

PHLF: Posthepatectomy liver failure; MVI: Microvascular invasion; AFP: Alphafetoprotein; IL-6: Interleukin-6; PVTT: Portal vein tumor thrombus

\section{Acknowledgements}

Not applicable

\section{Authors' contributions}

WP offered the idea of this study, analyzed the patient data, and drafted the manuscript. XYZ and CL performed the statistical analysis and revised the manuscript. TFW revised the manuscript and did a lot of work in data collection. ZYC was the supervisor of this study and was a major contributor in writing the manuscript. All authors read and approved the final manuscript. 


\section{Funding}

This work was supported by grants from the State Key Scientific and Technological Research Programs (2017ZX10203207-003-0020), the National Natural Science Foundation of China (81900463 and 81900576), and the Science and Technological Supports Project of Sichuan Province (2018JY0544). The funders had no role in study design, data collection and analysis, decision to publish, or preparation of the manuscript.

\section{Availability of data and materials}

The datasets generated and/or analyzed during the current study are not publicly available due to patient privacy but are available from the corresponding author on reasonable request.

\section{Ethics approval and consent to participate}

The study was approved by the Ethics Committee of West China Hospital, Sichuan University.

\section{Consent for publication}

Not applicable.

\section{Competing interests}

The authors declare that they have no competing interests.

Received: 5 July 2020 Accepted: 1 February 2021

Published online: 11 February 2021

\section{References}

1. Bray F, Ferlay J, Soerjomataram I, et al. Global cancer statistics 2018: GLOBOCAN estimates of incidence and mortality worldwide for 36 cancers in 185 countries. CA Cancer J Clin. 2018;68:394-424.

2. Feng RM, Zong YN, Cao SM, Xu RH. Current cancer situation in China: good or bad news from the 2018 Global Cancer Statistics? Cancer Commun (Lond). 2019;39:22

3. Zheng J, Chou JF, Gonen M, et al. Prediction of hepatocellular carcinoma recurrence beyond Milan criteria after resection: validation of a clinical risk score in an international cohort. Ann Surg. 2017:266:693-701.

4. Chapman WC, Klintmalm G, Hemming A, et al. Surgical treatment of hepatocellular carcinoma in North America: can hepatic resection still be justified? J Am Coll Surg. 2015;220:628-37.

5. Poon RT, Fan ST, Lo CM, et al. Long-term survival and pattern of recurrence after resection of small hepatocellular carcinoma in patients with preserved liver function: implications for a strategy of salvage transplantation. Ann Surg. 2002;235:373-82.

6. Chauhan A, Adams DH, Watson SP, Lalor PF. Platelets: no longer bystanders in liver disease. Hepatology. 2016;64:1774-84.

7. Philippe C, Philippe B, Fouqueray B, et al. Protection from tumor necrosis factor-mediated cytolysis by platelets. Am J Pathol. 1993;143:1713-23.

8. Wang YH, Kang JK, Zhi YF, et al. The pretreatment thrombocytosis as one of prognostic factors for gastric cancer: a systematic review and meta-analysis. Int J Surg. 2018;53:304-11.

9. Gu D, Szallasi A. Thrombocytosis portends adverse prognosis in colorectal cancer: a meta-analysis of 5,619 patients in 16 individual studies. Anticancer Res. 2017;37:4717-26.

10. Lee M, Chung GE, Lee JH, et al. Antiplatelet therapy and the risk of hepatocellular carcinoma in chronic hepatitis B patients on antiviral treatment. Hepatology. 2017;66:1556-69.

11. Lee PC, Yeh CM, Hu YW, et al. Antiplatelet therapy is associated with a better prognosis for patients with hepatitis B virus-related hepatocellular carcinoma after liver resection. Ann Surg Oncol. 2016;23:874-83.

12. Lee TY, Hsu YC, Tseng HC et al. Association of daily aspirin therapy with risk of hepatocellular carcinoma in patients with chronic hepatitis B. JAMA Intern Med 2019.

13. Mehrabi A, Golriz M, Khajeh E, et al. Meta-analysis of the prognostic role of perioperative platelet count in posthepatectomy liver failure and mortality. Br J Surg. 2018;105:1254-61.

14. Amano H, Tashiro H, Oshita A, et al. Significance of platelet count in the outcomes of hepatectomized patients with hepatocellular carcinoma exceeding the Milan criteria. J Gastrointest Surg. 2011;15:1173-81.

15. Roayaie S, Obeidat K, Sposito C, et al. Resection of hepatocellular cancer $\leq 2$ cm: results from two Western centers. Hepatology. 2013;57:1426-35.
16. Wu WC, Chiou YY, Hung HH, et al. Prognostic significance of computed tomography scan-derived splenic volume in hepatocellular carcinoma treated with radiofrequency ablation. J Clin Gastroenterol. 2012;46:789-95.

17. Kao WY, Chiou YY, Hung HH, et al. Younger hepatocellular carcinoma patients have better prognosis after percutaneous radiofrequency ablation therapy. J Clin Gastroenterol. 2012;46:62-70.

18. Bihari C, Rastogi A, Shasthry SM, et al. Platelets contribute to growth and metastasis in hepatocellular carcinoma. Apmis. 2016;124:776-86.

19. Morimoto $\mathrm{Y}$, Nouso K, Wada N, et al. Involvement of platelets in extrahepatic metastasis of hepatocellular carcinoma. Hepatol Res. 2014;44: E353-9.

20. Cheng YQ, Wang $K$, Zhang XP, et al. Thrombocytopenia: a prognostic factor for hepatocellular carcinoma patients with portal vein tumor thrombus after hepatectomy. J Gastroenterol Hepatol. 2018.

21. Scheiner B, Kirstein M, Popp S, et al. Association of platelet count and mean platelet volume with overall survival in patients with cirrhosis and unresectable hepatocellular carcinoma. Liver Cancer. 2019:8:203-17.

22. Hayashi H, Beppu T, Shirabe K, et al. Management of thrombocytopenia due to liver cirrhosis: a review. World J Gastroenterol. 2014;20:2595-605.

23. Wen $T$, Jin C, Facciorusso A, et al. Multidisciplinary management of recurrent and metastatic hepatocellular carcinoma after resection: an international expert consensus. Hepatobiliary Surg Nutr. 2018;7:353-71.

24. Kaser A, Brandacher G, Steurer W, et al. Interleukin-6 stimulates thrombopoiesis through thrombopoietin: role in inflammatory thrombocytosis. Blood. 2001;98:2720-5.

25. lannacone M, Sitia G, Narvaiza I, et al. Antiplatelet drug therapy moderates immune-mediated liver disease and inhibits viral clearance in mice infected with a replication-deficient adenovirus. Clin Vaccine Immunol. 2007;14: 1532-5.

26. Palumbo JS, Talmage KE, Massari JV, et al. Platelets and fibrin(ogen) increase metastatic potential by impeding natural killer cell-mediated elimination of tumor cells. Blood. 2005;105:178-85.

27. Franco AT, Corken A, Ware J. Platelets at the interface of thrombosis, inflammation, and cancer. Blood. 2015;126:582-8.

28. Afdhal N, McHutchison J, Brown R, et al. Thrombocytopenia associated with chronic liver disease. J Hepatol. 2008;48:1000-7.

29. Giannini E, Botta F, Borro P, et al. Relationship between thrombopoietin serum levels and liver function in patients with chronic liver disease related to hepatitis C virus infection. Am J Gastroenterol. 2003;98:2516-20.

30. Kang CM, Choi GH, Kim DH, et al. Revisiting the role of nonanatomic resection of small ( $<$ or $=4 \mathrm{~cm}$ ) and single hepatocellular carcinoma in patients with well-preserved liver function. J Surg Res. 2010;160:81-9.

31. Tsochatzis EA, Bosch J, Burroughs AK. Liver cirrhosis. Lancet. 2014;383:174961.

32. Poon RTP, Fan ST, Wong J. Risk factors, prevention, and management of postoperative recurrence after resection of hepatocellular carcinorna. Annals of Surgery. 2000;232:10-24.

33. Kubo S, Tanaka H, Shuto $T$, et al. Correlation between low platelet count and multicentricity of hepatocellular carcinoma in patients with chronic hepatitis C. Hepatol Res. 2004;30:221-5.

34. Nouso K, Matsumoto E, Kobayashi Y, et al. Risk factors for local and distant recurrence of hepatocellular carcinomas after local ablation therapies. J Gastroenterol Hepatol. 2008:23:453-8.

35. Xue TC, Ge NL, Xu X, et al. High platelet counts increase metastatic risk in huge hepatocellular carcinoma undergoing transarterial chemoembolization. Hepatol Res. 2016;46:1028-36.

36. Tao Y, Li Y, Liu X, et al. Nonsteroidal anti-inflammatory drugs, especially aspirin, are linked to lower risk and better survival of hepatocellular carcinoma: a meta-analysis. Cancer Manag Res. 2018:10:2695-709.

37. Jankowska H, Hooper P, Jankowski JA. Aspirin chemoprevention of gastrointestinal cancer in the next decade. A review of the evidence. Pol Arch Med Wewn. 2010;120:407-12.

38. Leng J, Han C, Demetris AJ, et al. Cyclooxygenase-2 promotes hepatocellular carcinoma cell growth through Akt activation: evidence for Akt inhibition in celecoxib-induced apoptosis. Hepatology. 2003;38:756-68.

39. Kurokawa T, Ohkohchi N. Platelets in liver disease, cancer and regeneration. World J Gastroenterol. 2017;23:3228-39.

\section{Publisher's Note}

Springer Nature remains neutral with regard to jurisdictional claims in published maps and institutional affiliations. 